\title{
Clinical Dental Hygienists' Awareness of the Medical Technicians Act and Clinical Performance in Korea
}

\author{
Song-I Back ${ }^{1}$ and Ji-Hyun Min ${ }^{2, \dagger}$ \\ 'Kimjiyong Dental Clinic, Cheongju 28325, \\ ${ }^{2}$ Department of Dental Hygiene, College of Medical and Health Sciences, Cheongju University, Cheongju 28503, \\ Korea
}

\begin{abstract}
Background: In Korea, laws for many medical technicians were revised in the Enforcement Decree of the Medical Technicians Act (MTA), which was announced on December 2018, whereas those related to dental hygienists remained unchanged. This study aimed to determine the awareness and opinions of dental hygienists regarding MTA.

Methods: Dental hygienist were recruited as participants via convenient sampling in Seoul, Gyeonggi-do, and Chungcheong-do; data from 291 self-reported questionnaire responses were used for the final analysis. We investigated the participants' general characteristics, awareness, and request for the amendment of the MTA. The compliance with the work scope specified in the MTA and level of demand for revision of the MTA were analyzed by independent t-test and one-way analysis of variance. For all statistical analyses, the significance level was set at 0.05 .

Results: For the 2018 MTA revision, 99 (34.02\%) knew that dental treatment assistance and surgery assistance were excluded, whereas $192(65.98 \%)$ did not know. The item "The current medical technician law must be revised" was scored $4.13 \pm 0.80$ out of 5 points, and significant differences were identified according to the education level, career, and position $(p<0.05)$. The item "It is necessary to institutionalize the expanded work scope beyond the work scope of dental hygienists specified in the MTA" was scored $4.02 \pm 1.04$ out of 5 points, and significant differences were identified according to age $(p<0.05)$.

Conclusion: The participants wanted the MTA to be revised to reflect the real-world work performed by dental hygienists in the dental clinical field. The legal system must ensure the legal protection of the work area of the dental hygienist as an oral health professional, and recognize the legal work scope of the dental hygienist.
\end{abstract}

Key Words: Awareness, Clinical performance, Dental hygienist, Medical technicians act

\section{Introduction}

The dental hygienist is an oral health professional who prevents and treats oral diseases with dentists after passing the national exam conducted by the Korea Health Personnel Licensing Examination Institute and then obtaining a license from the Minister of Health and Welfare ${ }^{1)}$. Previously, before dental assistants were produced through regular education courses, nurses trained to assist doctors who performed dental services. Korean dental hygienists were first defined by law in 1973, which was revised in
October 1995 and again in May 2012. Currently, dental hygienists are defined in the Medical Technicians Act of Korea (enforced December 20, 2018, MTA) as a type of medical technician. The legal scope of work of dental hygienists was first defined as "work on the prevention and hygiene of dental and oral diseases" in accordance with the MTA and its implementing ordinances of 1973. In 1996, "the removal of calculus scaling, the application of fluoride, and radiography for intraoral diagnosis" was specifically introduced. In 2015, the tasks of "temporary filling, temporary attachment installation, attachment 
removal, dental impression, orthodontic wire installation, and removal" were specified ${ }^{2}$. Stipulations for other medical technician occupational groups were revised in accordance with the implementing ordinances of the MTA, announced on December 18, 2018; meanwhile, the laws related to dental hygienists were maintained. According to Article 2 of the implementing ordinances of MTA, the scope of work for dental hygienists is defined as follows: orthodontic wire installation and removal, application of fluoride, radiography for intraoral diagnosis, temporary filling, installation and removal of temporary attachments, removal of deposits (e.g., dental calculus), dental impression, and other tasks related to the prevention of dental and oral diseases and hygiene management. However, the scope of the work performed by dental hygienists under the management and guidance of dentists in dental clinics is broader than that described in the implementing ordinances of the MTA. As such, the law does not properly reflect reality. Indeed, dental treatment assistance, which is mainly performed by dental hygienists in the clinical field, has been claimed to be illegal because "dental care aid and surgical aid" tasks are not explicitly indicated in $\mathrm{MTA}^{3)}$. To date, the law recognizes dental hygienists, nurses and nursing assistants, and dental medical personnel, including dental technicians and radiologists. To address the conflict in the field of dental work among professionals, the Korean Dental Hygienists Association has posted on the Blue House petition website, implemented a ribbon campaign to inform and call for the revision of the legal scope of work of dental hygienists, and conducted a signature campaign to have the medical law amended to recognize dental hygienists as medical personnel.

As the paradigm of dental treatment changes from treatment to oral health promotion, the role of the dental hygienists should expand to improve dental care more qualitatively and bolster productivity ${ }^{4}$. However, there is a gap between the legally prescribed and actually performed work of the dental hygienist ${ }^{5}$, and owing to social needs, dental treatment assistance and cooperation occupy a significant portion of the work of the dental hygienist. Consequently, legal controversies over the delegated dental treatment and dental treatment assistance are constantly intensifying and conflicts with other occupations are growing. Dental hygienists, along with dentists, are professionals who face patients directly in clinical practice $^{1)}$, and should strive to promote the public's oral health with professionalism and a sense of mission. However, if the professionalism of the dental hygienist is not recognized owing to the barriers of the law, then the satisfaction with the dental hygienists' work will be lowered and dental hygiene activities will contract. Such a scenario makes it difficult to provide high-quality dental services, which in turn adversely affects the public's oral health. Interest in the legal scope of the work of dental hygienists has been increasing, and research on the awareness of MTA $^{6-8)}$ has been conducted among dental hygienists. However, after the announcement of the current maintenance of the implementing ordinances of the 2018 MTA, few studies have examined the perceptions of dental hygienists regarding their actual and legal scope of work. Therefore, this study aimed to determine the awareness of MTA, work suitability, and clinical performance of dental hygienists. We intended to call for a legal system that can legally protect the dental hygienist's work area and realize a practical legal work scope that can be used as a basic resource.

\section{Materials and Methods}

\section{Participants}

We recruited through convenience sampling 231 dental hygienists working at primary dental hospitals in Seoul, Gyeonggi Province, and Chungcheong Province and 60 dental hygienists working at secondary and tertiary dental hospitals to participate in the self-administered survey. The investigation was conducted from June to July 2019.

We only included dental hygienists who agreed to participate in the study and submitted their consent via mobile message after listening to the explanation of the meaning and purpose of the study in advance. We explained that participation could be canceled at any time in the course of participation in the study, that the collected data would not be used for purposes other than the study objectives, and that confidentiality was guaranteed by all participants being treated as anonymous. 
The necessary number of participants was calculated as 200 people when the significance level was set at 0.05 , power at 0.80 , and effect size at 0.25 in the $\mathrm{G}^{*}$ power 3.1 program to perform one-way analysis of variance. A total of 320 people were surveyed. Data from 291 were used for the final analysis; data from 29 people who did not respond were excluded.

\section{Study variables}

\section{1) General characteristics of participants}

The general characteristics of the participants, such as age, marital status, educational background, clinical career, work position, type of medical institution, and monthly income (after-tax income) were investigated.

Table 1. Difference of Recognition of the Medical Technicians Act according to General Characteristics

\begin{tabular}{|c|c|c|c|c|c|c|c|}
\hline \multirow[t]{2}{*}{ Characteristic } & \multirow[t]{2}{*}{ Total } & \multicolumn{2}{|c|}{$\begin{array}{c}\text { Recognition of the revision on } \\
\text { the } \text { MTA }^{\mathrm{a}}\end{array}$} & \multirow[t]{2}{*}{ p-value } & \multicolumn{2}{|c|}{$\begin{array}{l}\text { About becoming a dental } \\
\text { hygienist to be a medical } \\
\text { personnel }^{\mathrm{b}}\end{array}$} & \multirow[t]{2}{*}{$\mathrm{p}$-value } \\
\hline & & Yes & No & & Assent & Opposition & \\
\hline Age (y) & & & & 0.003 & & & 0.343 \\
\hline$\leq 25$ & $91(31.27)$ & $32(35.16)$ & $59(64.84)$ & & $90(98.90)$ & $1(1.10)$ & \\
\hline $26 \sim 30$ & $125(42.96)$ & $29(23.20)$ & $96(76.80)$ & & $117(93.60)$ & $8(6.40)$ & \\
\hline $31 \sim 35$ & $46(15.81)$ & $23(50.00)$ & $23(50.00)$ & & $44(95.65)$ & $2(4.35)$ & \\
\hline $36 \sim 40$ & $16(5.50)$ & $8(50.00)$ & $8(50.00)$ & & $15(93.75)$ & $1(6.25)$ & \\
\hline$\geq 41$ & $13(4.47)$ & $7(53.85)$ & $6(46.15)$ & & $13(100.00)$ & $0(0.00)$ & \\
\hline Marriage & & & & 0.792 & & & 0.350 \\
\hline Single & $226(77.66)$ & $76(33.63)$ & $150(66.37)$ & & $218(96.46)$ & $8(3.54)$ & \\
\hline Married & $65(22.34)$ & $23(35.38)$ & $42(64.62)$ & & $61(93.85)$ & $4(6.15)$ & \\
\hline Education level & & & & 0.024 & & & 0.241 \\
\hline College & $186(63.92)$ & $56(30.11)$ & $130(69.89)$ & & $180(96.77)$ & $6(3.23)$ & \\
\hline University & 87 (29.90) & $32(36.78)$ & $55(63.22)$ & & $81(93.10)$ & $6(6.90)$ & \\
\hline$\geq$ Graduate school & $18(6.19)$ & $11(61.11)$ & $7(38.89)$ & & $18(100.00)$ & $0(0.00)$ & \\
\hline Total years of career & & & & 0.210 & & & 0.373 \\
\hline$\leq 3$ & $104(35.74)$ & $39(37.50)$ & $65(62.50)$ & & $98(94.23)$ & $6(5.77)$ & \\
\hline $4 \sim 7$ & $103(35.40)$ & $33(32.04)$ & $70(67.96)$ & & $98(95.15)$ & $5(4.85)$ & \\
\hline $8 \sim 11$ & $50(17.18)$ & $12(24.00)$ & $38(76.00)$ & & $50(100.00)$ & $0(0.00)$ & \\
\hline$\geq 12$ & $34(11.68)$ & $15(44.12)$ & $19(55.88)$ & & $33(97.06)$ & $1(2.94)$ & \\
\hline Position & & & & 0.367 & & & 0.845 \\
\hline General dental hygienist & $199(68.38)$ & $66(33.17)$ & $133(66.83)$ & & $190(95.48)$ & $9(4.52)$ & \\
\hline Team leader & $53(18.21)$ & $16(30.19)$ & $37(69.81)$ & & $51(96.23)$ & $2(3.77)$ & \\
\hline Head dental hygienist & $39(13.40)$ & $17(43.59)$ & $22(56.41)$ & & $38(97.44)$ & $1(2.56)$ & \\
\hline Type of dental clinic & & & & 0.518 & & & 0.005 \\
\hline Dental office & $231(79.38)$ & $75(32.47)$ & $156(67.53)$ & & $224(96.97)$ & $7(3.03)$ & \\
\hline Dental hospital & $36(12.37)$ & $15(41.67)$ & $21(58.33)$ & & $31(86.11)$ & $5(13.89)$ & \\
\hline University hospital & $24(8.25)$ & $9(37.50)$ & $15(62.50)$ & & $24(100.00)$ & $0(0.00)$ & \\
\hline Monthly income (after-tax income) & & & & 0.017 & & & 0.131 \\
\hline$<180$ & $34(11.68)$ & $19(55.88)$ & $15(44.12)$ & & $34(100.00)$ & $0(0.00)$ & \\
\hline $180 \sim 220$ & $109(37.46)$ & $34(31.19)$ & $75(68.81)$ & & $101(92.66)$ & $8(7.34)$ & \\
\hline $220 \sim 260$ & $85(29.21)$ & $21(24.71)$ & $64(75.29)$ & & $81(95.29)$ & $4(4.71)$ & \\
\hline $260 \sim 300$ & $45(15.46)$ & $17(37.78)$ & $28(62.22)$ & & $45(100.00)$ & $0(0.00)$ & \\
\hline$\geq 300$ & $18(6.19)$ & $8(44.44)$ & $10(55.56)$ & & $18(100.00)$ & $0(0.00)$ & \\
\hline Total & & $99(34.02)$ & $192(65.98)$ & & $279(95.88)$ & $12(4.12)$ & \\
\hline
\end{tabular}

Values are presented as number $(\%)$.

${ }^{a}$ Whether or not to aware of the exclusion of 'dental treatment assistance and surgical assistance' in the revision of the Medical Technicians Act in 2018.

${ }^{b}$ Whether or not to agree that the dental hygienist become a medical personnel as the medical law is revised in the future.

p-values were obtained from chi-square test. 


\section{2) Recognition and opinions of Medical Technicians} Act

The study tools were based on the thesis of $\mathrm{Kim}^{9)}$ and survey questions in Choi et al. ${ }^{8)}$, modified to suit the purpose of the present research. The recognition of and opinions on MTA were investigated by formulating four questions on the degree of recognition of MTA, five questions on the level of demand for the revision of the MTA, and six questions on the suitability of the work scope of dental hygienists specified in the MTA. Two questions on the level of demand for the revision of the MTA and three questions on the suitability of work scope specified in the MTA were rated using a five-point Likert scale in which "Strongly Disagree" was scored point and "Strongly Agree," five points.

\section{3) Duties actually performed and duties recognized as specified in the law}

Among the tasks of dental hygienists presented in the study of Lee et al. ${ }^{2}$, we selected the contents with frequent problems from overlapping tasks among different occupations. In addition to the nine legal duties of dental hygienists under the MTA, 11 duties that were expected of dental hygienists to perform frequently in dental hospitals and clinics were selected. Thus, 20 questions were composed. Duties actually performed and duties recognized as the legal scope of the work were calculated in percentages.

\section{Data analysis}

To identify the general characteristics, and recognition of and opinions on the MTA of the participants, we conducted technical statistical analyses of frequency, percentage, average, and standard deviation. Whether the MTA was recognized or not according to the general characteristics was tested with chi-square, and the compliance with the work scope specified in the MTA and level of demand for the revision of the MTA were analyzed by independent t-test and one-way analysis of variance. For all statistical analyses, the significance level of the test was based on 0.05 . The data collected were analyzed using the IBM SPSS Statistics 24.0 K Program for Windows (IBM Corp., Armonk, NY, USA).

\section{Results}

\section{Recognition of Medical Technicians Act}

Table 1 shows the results of the general characteristics of the participants regarding their recognition of the revision of the MTA and their consent to being recognized as medical personnel. For the 2018 MTA revision, 99 (34.02\%) knew that dental treatment assistance and surgery assistance were excluded, whereas 192 (65.98\%) did not know. On whether or not the participants were aware of the revision of the MTA, significant differences were identified depending on age, education level, and monthly income. Of the 99 people who were aware of the revision of the MTA, only $24.24 \%$ were satisfied with the revision, and the remaining $75.76 \%$ said they were dissatisfied. The 192 people who did not recognize the revision of the MTA stated their reason as follows: lack of publicity $(52.60 \%)$, lack of awareness $(31.77 \%)$, and no interest $(15.63 \%$ ) (Table 2). Significant differences were found in these responses according to age, educational background, and monthly income (after-tax income) type (Table 1). A large majority of the participants (279, $95.88 \%$ ) answered that they would approve that the dental hygienist be recognized as medical personnel through a revision of the medical law in the future, whereas 12 (4.12\%) expressed disapproval. Significant differences were found in these responses depending on the type of dental clinic ( $\mathrm{p}=0.005$, Table 1$)$.

Table 2. The Recognition of the Medical Technicians Act

\begin{tabular}{lr}
\hline \multicolumn{1}{c}{ Classification } & $\mathrm{n}(\%)$ \\
\hline $\begin{array}{l}\text { 1. Only those who were aware of the revision of } \\
\text { the Medical Articles Act were asked.: }\end{array}$ & $99(100)$ \\
Are you satisfied with 'Maintaining the current & \\
status' of the revised Medical Technicians Act? & \\
$\quad$ Satisfaction & $24(24.24)$ \\
$\quad$ dissatisfaction & $75(75.76)$ \\
2. Only those who were not aware of the revision & $192(100)$ \\
of the Medical Articles Act were asked.: & \\
If you aren't aware of the revision of Medical & \\
Technicians Act, why? & $30(15.63)$ \\
No interest & $101(52.60)$ \\
Lack of publicity & $61(31.77)$ \\
\hline Lack of awareness & \\
\hline
\end{tabular}




\section{Duties actually performed and duties recognized as specified in the law}

Twenty kinds of duties were selected, and the participants were asked to select all the duties they were actually performing in the clinic. They were also asked to identify the nine duties recognized as being specified in the law.

The results indicated that topical anesthesia showed the greatest difference of $65.98 \%$ between duties actually performed and duties recognized as specified in the law. The majority (89.69\%) of the participants were applying topical anesthesia, which was the most common task. Meanwhile, only $23.71 \%$ of the participants perceived topical anesthesia as among the duties recognized as specified in the law. Temporary crown production and radiography showed large gaps between duties actually performed and duties recognized as specified in the law. Meanwhile, we observed no difference between the number of participants who chose extraction of primary teeth as among the duties actually being performed and those who chose it as among the duties recognized as specified in the law (Table 3 ).

\section{Suitability of legal work scope of dental hygienists and demand for revision of the Act}

Table 4 shows the results of the verification of the suitability of the work scope of dental hygienists specified in the MTA and the level of demand for the revision of the MTA by general characteristics. The survey was rated on a five-point scale from 5 (strongly agree) to 1 (strongly disagree). The items "The current MTA should be revised," "It is necessary to institutionalize the expanded work scope beyond the work scope of dental hygienists specified in the MTA," and "The work scope of dental hygienists in the MTA should include medical assistance and surgical assistance," showed similar results of being rated four points. "The work scope of dental hygienists specified in the MTA includes the actual clinical practice" was rated $2.83 \pm 1.14$ points. "Overall, I am satisfied with the system

Table 3. The Order of Duties Actually Being Performed and the Order of Duties Recognized as Being Specified in the Law

\begin{tabular}{|c|c|c|c|}
\hline Type of work & $\begin{array}{l}\text { Duties actually being } \\
\text { performed }\end{array}$ & $\begin{array}{c}\text { Duties recognized as } \\
\text { being specified in the law }\end{array}$ & $\begin{array}{l}\text { Ratio difference }^{\mathrm{a}} \\
( \pm \%)\end{array}$ \\
\hline Topical anesthesia & $261(89.69)$ & $69(23.71)$ & 65.98 \\
\hline Temporary crown production & $211(72.51)$ & $63(21.65)$ & 50.86 \\
\hline Radiography of CT & $191(65.64)$ & $61(20.96)$ & 44.68 \\
\hline Record of medical records & $150(51.55)$ & $42(14.43)$ & 37.12 \\
\hline Dental treatment assistance and surgical assistance & $244(83.85)$ & $165(56.70)$ & 27.15 \\
\hline Dressing & $103(35.40)$ & $28(9.62)$ & 25.78 \\
\hline Final Setting of prosthesis & $88(30.24)$ & $16(5.50)$ & 24.74 \\
\hline Gingival retraction & $192(65.98)$ & $127(43.64)$ & 22.44 \\
\hline Removing the thread (stich out) & $67(23.02)$ & $10(3.44)$ & 19.58 \\
\hline Adjustment of occlusion & $59(20.27)$ & $4(1.37)$ & 18.9 \\
\hline Installation of temporary attachments & $166(57.04)$ & $114(39.18)$ & 17.86 \\
\hline Temporary filling & $191(65.64)$ & $160(54.98)$ & 10.66 \\
\hline Orthodontic wire installation and removal & $146(50.17)$ & $168(57.73)$ & 7.56 \\
\hline Removal of deposits such as dental calculus & $258(88.66)$ & $276(94.85)$ & 6.19 \\
\hline The application of fluoride & $253(86.94)$ & $270(92.78)$ & 5.84 \\
\hline Dental impression & $245(84.19)$ & $228(78.35)$ & 5.84 \\
\hline Removal of temporary attachments & $220(75.60)$ & $203(69.76)$ & 5.84 \\
\hline Intraoral/extraoral radiography (peri-apical radiography, panorama) & $258(88.66)$ & $246(84.54)$ & 4.12 \\
\hline Prevention of dental and oral diseases and hygiene management & $244(83.85)$ & $246(84.54)$ & 0.69 \\
\hline Extraction of primary teeth & $13(4.47)$ & $13(4.47)$ & 0 \\
\hline
\end{tabular}

Values are presented as number (\%).

CT: computed tomography.

${ }^{a}$ Ratio difference in ratio between duties actually being performed and duties recognized as being specified in the law. 
Table 4. The Awareness of Suitability of the Work Scope of Dental Hygienists Specified in the Medical Technicians Act and Level of Demand for Revision of the Medical Technicians Act by General Characteristics

\begin{tabular}{|c|c|c|c|c|c|}
\hline Characteristic & Q 1 & Q 2 & Q 3 & Q 4 & Q 5 \\
\hline \multicolumn{6}{|l|}{ Age $(y)$} \\
\hline$\leq 25$ & $3.02 \pm 1.18$ & $4.21 \pm 0.70$ & $4.22 \pm 0.92^{\mathrm{ab}}$ & $4.30 \pm 0.93$ & $2.65 \pm 0.76$ \\
\hline $26 \sim 30$ & $2.82 \pm 1.09$ & $4.05 \pm 0.84$ & $3.90 \pm 1.08^{\mathrm{ab}}$ & $3.97 \pm 1.06$ & $2.48 \pm 0.80$ \\
\hline $31 \sim 35$ & $2.74 \pm 1.08$ & $4.11 \pm 0.87$ & $4.02 \pm 0.97^{\mathrm{ab}}$ & $3.87 \pm 1.00$ & $2.59 \pm 0.80$ \\
\hline $36 \sim 40$ & $2.56 \pm 1.26$ & $4.06 \pm 0.92$ & $3.44 \pm 1.36^{\mathrm{a}}$ & $3.94 \pm 1.06$ & $2.50 \pm 1.03$ \\
\hline$\geq 41$ & $2.23 \pm 1.23$ & $4.62 \pm 0.50$ & $4.46 \pm 0.87^{\mathrm{b}}$ & $4.23 \pm 1.01$ & $2.69 \pm 1.25$ \\
\hline p-value & 0.119 & 0.133 & 0.015 & 0.981 & 0.620 \\
\hline \multicolumn{6}{|l|}{ Marriage } \\
\hline Single & $2.85 \pm 1.12$ & $4.11 \pm 0.82$ & $4.00 \pm 1.04$ & $4.06 \pm 1.01$ & $2.54 \pm 0.75$ \\
\hline Married & $2.77 \pm 1.20$ & $4.23 \pm 0.74$ & $4.08 \pm 1.05$ & $4.08 \pm 1.03$ & $2.63 \pm 1.05$ \\
\hline p-value & 0.618 & 0.272 & 0.622 & 0.917 & 0.518 \\
\hline \multicolumn{6}{|l|}{ Education level } \\
\hline College & $2.99 \pm 1.14^{\mathrm{ab}}$ & $4.13 \pm 0.75^{\mathrm{a}}$ & $4.01 \pm 1.02$ & $4.00 \pm 1.02$ & $2.56 \pm 0.81$ \\
\hline University & $2.63 \pm 1.08^{\mathrm{b}}$ & $4.02 \pm 0.90^{\mathrm{a}}$ & $3.95 \pm 1.12$ & $4.10 \pm 1.03$ & $2.62 \pm 0.76$ \\
\hline$\geq$ Graduate school & $2.17 \pm 1.09^{\mathrm{a}}$ & $4.67 \pm 0.59^{\mathrm{b}}$ & $4.44 \pm 0.78$ & $4.56 \pm 0.70$ & $2.28 \pm 1.17$ \\
\hline p-value & 0.002 & 0.008 & 0.189 & 0.080 & 0.281 \\
\hline \multicolumn{6}{|l|}{ Total career (y) } \\
\hline$\leq 3$ & $2.98 \pm 1.07^{\mathrm{b}}$ & $4.09 \pm 0.80^{\mathrm{a}}$ & $3.95 \pm 1.05$ & $4.04 \pm 1.01$ & $2.72 \pm 0.71$ \\
\hline $4 \sim 7$ & $2.88 \pm 1.13^{\mathrm{b}}$ & $4.00 \pm 0.86^{\mathrm{a}}$ & $3.97 \pm 0.97$ & $4.06 \pm 0.97$ & $2.52 \pm 0.79$ \\
\hline $8 \sim 11$ & $2.84 \pm 1.14^{\mathrm{b}}$ & $4.36 \pm 0.59^{\mathrm{a}}$ & $4.26 \pm 1.00$ & $4.10 \pm 1.12$ & $2.44 \pm 0.90$ \\
\hline$\geq 12$ & $2.21 \pm 1.20^{\mathrm{a}}$ & $4.35 \pm 0.81^{\mathrm{a}}$ & $4.03 \pm 1.24$ & $4.12 \pm 1.03$ & $2.35 \pm 1.07$ \\
\hline p-value & 0.006 & 0.021 & 0.347 & 0.974 & 0.063 \\
\hline \multicolumn{6}{|l|}{ Position } \\
\hline General dental hygienist & $3.01 \pm 1.10^{\mathrm{b}}$ & $4.09 \pm 0.79^{\mathrm{a}}$ & $4.00 \pm 1.01$ & $4.01 \pm 1.03$ & $2.63 \pm 0.74^{\mathrm{b}}$ \\
\hline Team leader & $2.51 \pm 1.15^{\mathrm{a}}$ & $4.09 \pm 0.79^{\mathrm{a}}$ & $3.92 \pm 1.17$ & $4.15 \pm 0.96$ & $2.53 \pm 0.91^{\mathrm{ab}}$ \\
\hline Head dental hygienist & $2.36 \pm 1.13^{\mathrm{a}}$ & $4.44 \pm 0.82^{\mathrm{a}}$ & $4.26 \pm 1.01$ & $4.26 \pm 0.99$ & $2.26 \pm 1.06^{\mathrm{a}}$ \\
\hline p-value & $<0.001$ & 0.041 & 0.285 & 0.297 & 0.036 \\
\hline \multicolumn{6}{|l|}{ Type of dental clinic } \\
\hline Dental office & $2.90 \pm 1.14$ & $4.13 \pm 0.79$ & $4.00 \pm 1.04$ & $4.05 \pm 0.99$ & $2.57 \pm 0.85$ \\
\hline Dental hospital & $2.69 \pm 1.11$ & $3.97 \pm 0.94$ & $4.00 \pm 1.01$ & $3.86 \pm 1.24$ & $2.47 \pm 0.73$ \\
\hline University hospital & $2.38 \pm 1.13$ & $4.38 \pm 0.64$ & $4.21 \pm 1.14$ & $4.50 \pm 0.78$ & $2.58 \pm 0.77$ \\
\hline p-value & 0.074 & 0.165 & 0.656 & 0.053 & 0.793 \\
\hline \multicolumn{6}{|c|}{ Monthly income (after-tax income) } \\
\hline$<180$ & $3.02 \pm 1.18$ & $3.85 \pm 0.70$ & $3.68 \pm 0.80$ & $3.79 \pm 0.88$ & $2.94 \pm 0.69^{\mathrm{b}}$ \\
\hline $180 \sim 220$ & $2.82 \pm 1.09$ & $4.17 \pm 0.81$ & $4.11 \pm 1.08$ & $4.16 \pm 1.05$ & $2.48 \pm 0.76^{\mathrm{ab}}$ \\
\hline $220 \sim 260$ & $2.74 \pm 1.08$ & $4.05 \pm 0.85$ & $3.94 \pm 1.02$ & $3.95 \pm 1.06$ & $2.61 \pm 0.86^{\mathrm{ab}}$ \\
\hline $260 \sim 300$ & $2.56 \pm 1.26$ & $4.33 \pm 0.60$ & $4.13 \pm 1.03$ & $4.22 \pm 0.90$ & $2.51 \pm 0.89^{\mathrm{ab}}$ \\
\hline$\geq 300$ & $2.23 \pm 1.23$ & $4.33 \pm 0.97$ & $4.22 \pm 1.21$ & $4.17 \pm 1.04$ & $2.22 \pm 0.94^{\mathrm{a}}$ \\
\hline $\mathrm{p}$-value & 0.119 & 0.053 & 0.185 & 0.237 & 0.018 \\
\hline Total & $2.83 \pm 1.14$ & $4.13 \pm 0.80$ & $4.02 \pm 1.04$ & $4.07 \pm 1.02$ & $2.56 \pm 0.83$ \\
\hline
\end{tabular}

All values were shown as mean \pm standard deviation that obtained from the result of answer values (five-point scale: strongly agree $=5$, agree $=4$, neutral $=3$, disagree $=2$, strongly disagree $=1$ ).

Q 1. The work scope of the dental hygienists specified in the Medical Technicians Act includes the actual clinical practice.

Q 2. Currently the Medical Technicians Act needs to be revised.

Q 3. It is necessary to institutionalize the expanded work scope beyond the work scope of dental hygienists specified in the Medical Technicians Act.

Q 4. The work scope of dental hygienists in Medical Technicians Act should include 'dental treatment assistance and surgical assistance'.

Q 5. Overall, I am satisfied with the system related to dental hygienists in Medical Technicians Act.

${ }^{a, b}$ Different superscript letters denote significant differences between groups by Scheffe post hoc test $(\mathrm{p}<0.05)$.

p-values were obtained from independent t-test or one-way ANOVA test. 
related to dental hygienists in the MTA" scored even lower, at $2.97 \pm 0.83$ points. As for "I think the current MTA should be revised," significant differences were observed according to education level, career, and position. Significant differences in position and monthly

Table 5. Opinions Related to the Scope of Work of Dental Hygienists under the Medical Technician Act

\begin{tabular}{|c|c|}
\hline Classification & $\mathrm{n}(\%)$ \\
\hline $\begin{array}{l}\text { 1. Why did you do anything other than the work } \\
\text { scope of the dental hygienists specified in the } \\
\text { Medical Technician Act? }\end{array}$ & $291(100)$ \\
\hline Under the direction of the dentist & $157(53.95)$ \\
\hline $\begin{array}{l}\text { Under the direction of other superiors } \\
\text { except for the dentist }\end{array}$ & $72(24.74)$ \\
\hline $\begin{array}{l}\text { Because there were no other dental } \\
\text { assistants (dental technicians, nurse's aides) }\end{array}$ & $24(8.25)$ \\
\hline On my own will & $7(2.41)$ \\
\hline I have never done it & $31(10.65)$ \\
\hline $\begin{array}{l}\text { 2. What is the biggest problem in establishing the } \\
\text { dental hygienist's work scope in the current } \\
\text { Medical Technician Act? }\end{array}$ & $291(100)$ \\
\hline $\begin{array}{l}\text { Uncertainty in the location of the dental } \\
\text { hygienist system }\end{array}$ & $159(54.64)$ \\
\hline $\begin{array}{l}\text { Lack of dentist's awareness of segregation } \\
\text { of duties }\end{array}$ & $55(18.90)$ \\
\hline $\begin{array}{l}\text { Lack of dental hygienist's awareness of } \\
\text { segregation of duties }\end{array}$ & $50(17.18)$ \\
\hline Lack of dental hygienists & $18(6.19)$ \\
\hline Etc. & $7(2.41)$ \\
\hline No problem & $2(0.69)$ \\
\hline $\begin{array}{l}\text { 3. Do you think it makes sense to make a dental } \\
\text { hygienist a medical personnel? }\end{array}$ & $291(100)$ \\
\hline Yes & $252(86.60)$ \\
\hline No & $6(2.06)$ \\
\hline I don't know & $33(11.34)$ \\
\hline
\end{tabular}

income were found for the item "Overall, I am satisfied with the system related to dental hygienists in the MTA" $(\mathrm{p}<0.05$, Table 4).

Among the reasons for performing tasks other those specified in the MTA, "the dentist's order" was the most commonly cited $(53.95 \%)$, and only $10.65 \%$ of the participants answered that they had never performed anything other than the dental hygienist's work specified in the MTA.

Regarding the item "What is the biggest problem in establishing the dental hygienist's work area in the current MTA," the uncertainty of the scope of the dental hygienist system was the most common response (54.64\%); only $0.69 \%$ answered that there were no problems, and other opinions cited disputes over profits among dental workers and a lack of effort by the Dental Hygienists Association. A total of $86.60 \%$ of the participants agreed that "It is justifiable to treat dental hygienists as medical personnel" (Table 5).

Table 6 categorizes the dental hygienist's work into five categories and gives the ranking by item. We investigated the items according to perceived level of importance. Of the five tasks considered as the main duties of clinical dental hygienists, "dental treatment assistance" was the most selected duty as the priority among the most frequently performed duties $(59.45 \%)$. In addition, "dental treatment assistance" was the most selected as a priority duty to be considered if Article 3 (Scope and Limits) of the MTA were revised.

If dental hygienists become medical personnel with the

Table 6. Main Duties of Dental Hygienists and Future Prospects

\begin{tabular}{|c|c|c|c|c|c|c|}
\hline \multirow{2}{*}{ Main duty } & \multicolumn{2}{|c|}{ Q 1} & \multicolumn{2}{|c|}{ Q 2} & \multicolumn{2}{|c|}{ Q 3} \\
\hline & 1 st & 5 th & 1 st & 5 th & 1 st & 5 th \\
\hline Dental treatment assistance & $173(59.45)$ & $14(4.81)$ & $99(34.02)$ & $17(5.84)$ & $82(28.18)$ & $17(5.84)$ \\
\hline Clinic administration and management & $48(16.49)$ & $149(51.20)$ & $7(2.41)$ & $226(77.66)$ & $9(3.09)$ & $231(79.38)$ \\
\hline $\begin{array}{l}\text { Oral hygiene status observation and preliminary } \\
\text { dental examination }\end{array}$ & $46(15.81)$ & $41(14.09)$ & $73(25.09)$ & $22(7.56)$ & $93(31.96)$ & $11(3.78)$ \\
\hline Preventive dental treatment & $17(5.84)$ & $30(10.31)$ & $79(27.15)$ & $7(2.41)$ & $74(25.43)$ & $9(3.09)$ \\
\hline Oral health education & $7(2.41)$ & $57(19.59)$ & $33(11.34)$ & $19(6.53)$ & $33(11.34)$ & $23(7.90)$ \\
\hline
\end{tabular}

Values are presented as number (\%).

Q 1. What do you do the most?

Q 2. What is the first priority of work to be considered if Article 3 (Scope and Limits) of the Medical Technician Act was revised.

Q 3. When the dental hygienist becomes a medical personnel with the revision of the medical law, what capabilities should the dental hygienist develop to expand the role of the dental hygienist? 
revision of the MTA, oral hygiene status observation and preliminary dental examination were identified as the most important tasks for developing competency toward expanding the role of dental hygienists (31.96\%, Table 6).

\section{Discussion}

The legal scope of dental hygiene in Korea is narrow, in contrast to the case in Australia, Canada, and the United States. Many countries have established a dental assistant system with variations in roles and curriculum. The dental care assistant, whose work is handled by the dental hygienist in Korea, is entrusted as a nurse's aide. Dental hygienists outside Korea are mainly responsible for oral health education and preventive dentistry, and are active in this area as professionals. Therefore, in contrast to their counterparts in other countries, dental hygienists' oral health activities are limited in Korea ${ }^{10}$. In reality, Practically many tasks performed by dental hygienists in dental medical institutions are not regulated by law, and the division of work between dental hygienists and other health care workers is ambiguous, leading to conflicts" ${ }^{9}$. To identify and resolve these problems, scholars have examined the division of work and establishment of work areas in dental hygiene ${ }^{2,49-11)}$. The present study aimed to grasp the clinical dental hygienist's perceptions and opinions regarding the current maintenance of the dental hygienist law in the 2018 revision of the MTA in Korea.

In our study, $34.02 \%$ of dental hygienists recognized the exclusion of "dental treatment assistance and surgical assistance" in the 2018 MTA Enforcement Decree. Among them, the rate of dissatisfaction with the current maintenance of the amendment to the MTA was the highest at $75.76 \%$. Meanwhile, $65.98 \%$ were unaware of the revision of the MTA, and their most common reason was the lack of public relations $(52.60 \%)$.

Among dental hygienists with a graduate degree or higher, the rate of awareness of was higher than that of no awareness. Meanwhile, in those with a college degree, the rate of awareness of the MTA revision of the MTA was lower than the rate of non-awareness $(p=0.024)$. These results were in contrast to those in Choi et al. ${ }^{8)}$, which reported that the younger the age, the more accurate the awareness of the MTA, given the smaller number of years since their school education. However, the awareness rate of the MTA revision was lower than the non-awareness rate, which affirmed the results of Kim et al. ${ }^{6}$. . Therefore, the relevant authorities should conduct education on the revision of the MTA in universities. The Korean Dental Hygienist Association should also launch information campaigns so that members can know about the revisions of the law.

The item "Dental treatment assistance and surgical assistance should be added to the scope of the dental hygienist's work" was scored $4.07 \pm 1.02$ out of 5. Dental treatment assistance was given the highest priority for "the work that I do most" at $59.45 \%$ among the top five dental hygienists' work, outranking clinic administration and management, oral hygiene status observation and preliminary dental examination, preventive dental treatment, and oral health education. If Article 3 (Scope and Limits) of the MTA is revised, the primary tasks that should be considered first were rated as follows: dental treatment assistance (34.02\%), preventive dental treatment $(27.15 \%)$, oral hygiene status observation and preliminary dental examination (25.09\%), oral health education (11.34\%), and clinic administration and management $(2.41 \%)$. Similar results were found in studies that ranked the tasks performed by clinical dental hygienists ${ }^{9,11)}$. The reason may be that dental hygienists continuously want to be legally protected for the work they perform and to have the actual scope of their work recognized. The proportion of dental care cooperative work was also found to remain high in work centers. Therefore, legal protection is required for dental care cooperation among dental medical personnel.

In Lee et al. ${ }^{7)}$, the requirement for the revision of the MTA was scored higher than 4 out of 5. In Kim et al. ${ }^{6}$, $92.5 \%$ of the participants expressed that the MTA should be revised. The demand for the revision of the MTA was $4.13 \pm 0.80$ out of 5 points in our study, which was confirmed to be consistent with the high demand in previous studies. The item "The work area should be institutionalized more than the dental hygienist's work scope specified in the MTA" was scored $4.02 \pm 1.04$ points out of 5. Topical anesthesia, temporary crown production, and radiography showed the greatest differences of $65.98 \%, 50.86 \%$, and 
$44.68 \%$, respectively, between duties actually performed and duties recognized as specified in the law. Dental hygienists reported being forced to work despite knowing the big gap between real-world practice and legislation. However, items such as prevention of dental and oral diseases and hygiene management and extraction of primary teeth were found to have little difference between actual work and duties recognized as specified in the law. A reasons is that the demand for performance in clinical practice is low, and most dental hygienists do not consider it as among their legally mandated duties.

Satisfaction with the system related to dental hygienists in MTA was derived from the difference between the current job scope and the legally stipulated job scope. The item "Overall, I am satisfied with the system related to dental hygienists in the MTA" was scored low at $2.56 \pm 0.83$ points out of 5 . The most cited reason for performing other duties outside the scope of the dental hygienist's work specified in the MTA was "order of the dentist" at $53.95 \%$. This was also among the answers to "the biggest problem in establishing the dental hygienist's work area in the MTA," followed by the dentist's lack of recognition of work (18.90\%). In Kim ${ }^{9}, 61.5 \%$ confirmed the presence of division of labor, and the reason for its absence was the lack of recognition of the dentist's work and the lack of dental hygiene personnel. According to Park et al. ${ }^{10)}$, dentists want dental hygienists to perform treatment preparation and treatment counseling, preventive care, radiography for the diagnosis of premises, and treatment assistance, as well as receive re-education and expert education to be able to perform these smoothly. In addition, dentists believe that dental hygienists must perform a variety of tasks in addition to the dental hygienist's scope of work specified in the MTA ${ }^{12}$. Therefore, it is necessary to revise the law in relation to the real-world practice of dental hygienists; the law should reflect the opinions of dentists and dental hygienists who face patients directly and perform oral disease treatment and other treatment tasks.

Studies on recognizing dental hygienists as medical personnel have been conducted; the Korean Dental Hygienists Association is currently supporting the work of dental hygienists ${ }^{13-15)}$. Our results revealed the near- unanimous (95.88\%) approval among dental hygienists to be recognized as medical personnel in a future revision of the MTA.

If the dental hygienist is promoted to become medical personnel, the duties for which competency should be developed were prioritized as follows: oral hygiene status observation and preliminary dental examination (31.96\%), dental treatment assistance (28.18\%), preventive dental treatment $(25.43 \%)$, oral health education (11.34\%), and clinic management administration (3.09\%). For the dental hygienist to observe and promote oral hygiene status, they require autonomy when practicing oral hygiene status observation and preliminary dental examination. Professional responsibility and independence are important factors for the professionalization of dental hygiene. However, as dental hygienists in Korea are limited in the level and scope of work under the supervision of a dentist, reforms are needed so that dental hygienists can take independent decision-making responsibilities.

Establishing a professional occupation improves job performance and increases employment intention, thereby affecting the provision of high-quality medical services ${ }^{16}$. A dental hygienist is a professional who directly provides dental services with a dentist. If the division of duties through the rationalization of practical work becomes clear, then work satisfaction increases, eventually leading to the provision of specialized dental services. Therefore, the legal system needs to be reformed to guarantee the legal protection of the work area of the dental hygienist as an oral health professional, and to recognize the legal work scope of the dental hygienist.

This study was conducted by conveniently recruiting and researching clinical dental hygienists in Seoul, Gyeonggi, and Chungcheong-do as participants; as such, the results of research may not be generalized as the opinions of dental hygienists. However, there are not many studies on the MTA focusing on dental hygienists. In this regard, the present study showed dental hygienists' perception of MTA and scope of their work. Our findings may be used as basic data to enhance the status of the profession as well as to establish the dental hygienist's professional work area. In the future, research is needed for other dental personnel and all dental hygienists. 
Further research is also needed regarding the MTA reflecting and recognizing the actual work of the clinical dental hygienist.

\section{Notes}

\section{Conflict of interest}

No potential conflict of interest relevant to this article was reported.

\section{Ethical approval}

This study was approved by the Institutional Review Board of Cheongju University (1041107-201906-HR-027-01).

\section{Author contributions}

Concept development: Song-I Back, Ji-Hyun Min. Design: Song-I Back, Ji-Hyun Min. Supervision: Ji-Hyun Min. Data collection and processing: Song-I Back. Analysis and interpretation: Song-I Back. Writing and review: Song-I Back, Ji-Hyun Min.

\section{ORCID}

Song-I Back, https://orcid.org/0000-0002-0419-5656

Ji-Hyun Min, https://orcid.org/0000-0001-5177-7600

\section{References}

1. Lee SJ, Han GS: The ethical propensity, professionalism and ethical job behavior of clinical dental hygienists. J Korean Acad Oral Health 36: 238-248, 2012.

2. Lee HJ, Shin SJ, Bae SM, Shin BM: Issues and challenges of dental hygienist workforce policy in Korea. J Korea Contents Assoc 19: 409-423, 2019. https://doi.org/10.5392/JKCA.2019.19.02.409

3. Dentalfocus: Korea Dental Hygienists Association "dental hygienist 'medical assistance' work scope struggle". Retrieved January 26, 2019, from http://www.dentalfocus.co.kr/news/ articleView.html?idxno=21740(2018, December 28).

4. Kwon HG: Dental hygienist work area's reality and development direction. J Korea Dent Assoc 40: 969-970, 2002.

5. Moon SE, Hong SH, Kim NY: A qualitative research on work scope in dental healthcare hygienists. J Korean Soc Dent Hyg 19: 907-918, 2019. https://doi.org/10.13065/jksdh.20190077

6. Kim SI, Jun MK, Lee SM: Needs of revision of dental hygienist-related medical law. J Korean Soc Dent Hyg 16: 677-685, 2016. https://doi.org/10.13065/jksdh.2016.16.05.677

7. Lee HJ, Kwak JW, Lee DH, et al.: Awareness, need and demand for the amendment of medical device law according to the general characteristics of some dental hygienists. J Korean Dent Hyg Sci 1: 23-36, 2018.

8. Choi YR, Seo HY, Ryu EJ, Choi EM: Dental hygienists' awareness of medical technician jurisprudence. J Dent Hyg Sci 16: 495-501, 2016. https://doi.org/10.17135/jdhs.2016.16.6.495

9. Kim YS: A study on dental hygienists' duty range and allocation. Unpublished master's thesis, Dankook University, Seoul, 2007.

10. Park JH, Kim MS, Cho JW: Dentists opinions for dental hygienists roles in Korea. J Korean Acad Oral Health 34: 88-97, 2010.

11. Kim YS, Shin MW: A study on the current state and weight of dental hygienists' works. J Korean Acad Dent Hyg Educ 8: 161-175, 2008.

12. Han YK, Yu JS, Kim SH, Yang JY, Bae SM, Hwang SJ: The dentists' view of dental hygienist duties in Korea. J Dent Hyg Sci 20: 34-43, 2020. https://doi.org/10.17135/jdhs.2020.20.1.34

13. Lee DS, Han GS: Problems to solve and job enlargement on the inclusion of dental hygienists in the category of medical personnel. J Dent Hyg Sci 18: 340-348, 2018. https://doi.org/10.17135/jdhs.2018.18.6.340

14. Hyeong JH, Jang YJ: The opinions of health care workers on the inclusion of dental hygienists in the category of medical personnel. J Korean Soc Dent Hyg 17: 1013-1024, 2017. https://doi.org/10.13065/jksdh.2017.17.06.1013

15. Ryu HG: The opinions of some local clinical dental hygienists on medical personnel of dental hygienists. J Korean Soc Dent Hyg 18: 1067-1077, 2018. https://doi.org/10.13065/jksdh.20180092

16. Kwon KJ, Ko KH, Kim KW, Kim JA: The impact of nursing professionalism on the nursing performance and retention intention among psychiatric mental health nurses. J Korean Acad Nurs Adm 16: 229-239, 2010. https://doi.org/10.11111/jkana.2010.16.3.229 